http://www.jfas.info

\title{
THE EFFECT OF HEALTH WORKERS' PERFORMANCE ON IMPLEMENTATION OF THE REFERRAL SYSTEM IN FAMILY PHYSICIAN PROGRAM IN RAMIAN CITY
}

\author{
A. Zahra Asadi ${ }^{1, *}$, B. Iravan Masoudi Asl, $\mathrm{PhD}^{2}$ and C. Sayed Jamale Din Tabibi, $\mathrm{PhD}^{3}$ \\ ${ }^{1}$ Masters of Health Services Management ,public health expert in Health center in Ramian \\ city, Golestan medical university, Golestan, Iran \\ ${ }^{2}$ Assistant professor, Health Services Management Department, School of Medical Sciences, \\ Islamic Azad university ,Science and Research branch, Tehran,Iran \\ ${ }^{3}$ Professor, Health Services Management Department, School of Medical Sciences, Islamic \\ Azad university ,Science and Research branch, Tehran,Iran
}

Published online: 15 May 2016

\begin{abstract}
According to the fact that providing service in rural community is done by health workers and based on the referral system the client refers to health workers first. so in case of not paying any attention to their performance, there will be a possibility of having problems. This research is sectional, applied and uses correlation method. The statistical society is consisted of health workers that were studied by census method. The data was analyzed by a psychometric, researcher-made questionnaire. After completing the questionnaire, the data was analyzed by using SPSS.According to the results, $4,6 \%$ had good awareness and $23,3 \%$
\end{abstract}

Author Correspondence, e-mail: asadi301@ yahoo.com doi: http://dx.doi.org/10.4314/jfas.v8i3s.261 
had a positive attitude and $100 \%$ had poor performance and fairly good. The results indicates that due to the role of health workers in the referral system, there is a requirement for identification and implementation of the factors that have a positive effect on this relationship. Keywords: Health worker; Referral system; Family Physician Program.

\section{INTRODUCTION}

The goal of development is nothing more satisfying the people's living conditions, since without health, no one is satisfied with his life so the establishment of the health system is one of the fundamental pillars of development. Health care system is organized in order to be more efficient and effective to create equity and access to three levels of the people in categories of first, second, and third, Given the level of service people have access to specialized services than is possible through the referral system.[1]

Referral system is a system under which, referring to health workers must be first done in health services centers (home health care) and, if necessary consult with the referring physician health workers to visit families And, if necessary, with rural insurance should be introduced to specialized doctors, after the necessary remedial measures and recommendations and their reflection in the form of feedback, Refer the patient to continue treatment referral source.

Health workers are also a member of the health team and since the members of the group are directly linked with population, can be covered in a more effective role in achieving the goal of health. It may therefore explicitly be stating that if health workers play their role in the group correctly without doubt it would be counted as one of the most influential members of the health team.[2]

Family doctors and health workers as complementary to each other, this is the route that was started by the health worker and later all feedbacks must return to health workers as well. So we should keep the focus on health workers in order to guarantee the health of the community.[3]

Since the beginning of its motion in the family doctor's referral system it has been unable to act so efficient and coordinated that could answer patients needs.[4] 
The results of the studies indicate that If the level of service can be organized within the referral system, 80 to 90 percent of the health needs can be met.[5]

Coleman revealed in his studies that $55 \%$ of patients with non-emergency problems that come to the emergency department could have been cared by general practitioners or are just recommendations.[6]

According to Ostvar et al reported on the attitude of health workers towards referral system was noticed that $27.5 \%$ of health workers from lack of training or inadequate training were grumbling about the referral system. 51 percent of health workers believe that patients who are referred to higher centers have not seen any priority in their admissions $75 / 5 \%$ of health workers have announced the referral of patients into rarely prosecuted.[7]

The results of Karimi et al showed that 54/6\% are highly knowledged health workers, 34/9\% intermediate and 10/5\% had poor knowledge about maternal health, plus 76/8\% had a good attitude. While only 18/6\% had good performance in this area. Also, the knowledge, attitude and practice study there was a significant relationship between education level and gender.[8] Balali Maibodi et al in the study of the knowledge, attitude and practice of health workers working in the field of oral health in the province of Kerman that total, $13 / 3 \%$ of health workers have good knowledge and $24 / 4 \%$ have a positive attitude and no health providers training courses did not obtain the optimum performance. Knowledge and attitudes to gender, education level showed significant relationship so that women who have more knowledge and attitudes were more positive.]9]

In another study the knowledge, attitude and practice of Tabriz's school health workers about oral health was evaluated In this study, the mean score of knowledge, attitude and performance, respectively, 6/77, 7/42 and 7/14 of the maximum score was 10 that women had significantly higher scores.[10]

The study conducted by Naghibi et al, moderate to good knowledge, good attitude and practice of breast self-examination in female health workers was also indicated in Maku city.[11]

Khani study et al showed that awareness of breast cancer prevention and screening programs in $41 / 3 \%$ health professionals good, $52 \%$ moderate and 6/7\% has been bad. Almost all 
respondents strongly agree or agree with the attitude breast cancer prevention programs. But in practice, only $26 / 2 \%$ of the participants were doing it monthly. $94 / 7 \%$ health workers participated in this study, are willing to participate in training programs, cancer prevention have been especially breast cancer.[12]

In another study in Japan in the field of oral health-related factors were analyzed according to sex it was revealed that the scale of good behaviour in each item of dental health, was higher remarkably among women than men.[13]

The results of the study conducted by Al-Erian et al also showed that the knowledge of doctors is enough but their prespective and function need modifications.[14]

Given that health workers as the linchpin in providing services to rural communities[15] and without their efforts as the first members of the health team and providing services, implementing the referral system will be troubled. [16]And in case of lack of attention to Mlkrdanan assessment, the possibility of problems regarding follow up and referral will be made. Evaluation services, health workers can find problems and obstacles in the implementation of health programs to help executives health system[17]Therefore, the study with the hypothesis that the performance of health workers has a significant impact on the implementation of the referral system in family physician program and To determine the impact of the implementation of the referral system was the performance of health workers In this context necessary to determine the need for intervention.

\section{MATERIAL AND METHOD}

This study is a cross-sectional study was conducted in 2015 .The range of this study covered all health centers and community health centers for Ramian city's health research, and health workers who were employed. People were studied by census method.

A questionnaire was used to collect data. The questionnaires were arranged in four main categories. The first part was related to demographic and work subjects.

The second part consisted of three distinct parts.

1-questions related to 4 options with a correct answer 26 questions about the scope of knowledge score between 0 and 26, respectively. 2. The question of the attitude contains 15 
questions with 7 items completely disagree, disagree, somewhat disagree, idea, somewhat agree, agree, agree completely burnt out the question based on the Likert scale was rated from 1 to 7. 3-question related to actions with respect to four main target groups (children under 5 years of age, adolescents, pregnant mothers and non-communicable) consists of 18 questions measure both quantitative and qualitative selection includes 4 options occurring any questions at all not done (code 1), is partially done (code 2) and completely done (code 3) and not mentioned (code 4). Function assessment in the present study was thus based on the Office system of care to each of the target groups in January 2015 the Health records of at least six recipients selected randomly and the timeliness of care and identifying cases referred to special care and rural health centers, accurate and timely follow-up references, registered care information, follow up and referral of patients was studied. If the process of $80-100 \%$ correct and timely referral system was registered Code 3, between 20-80\% Code 2 and less than 20\% Code 1 and if the activity was not related to sanitation and health workers went code 4 .

The average score of less than $50 \%$ response questions were considered inadequate knowledge, negative attitude and poor performance, responsiveness, knowledge and attitude between $50 \%-75 \%$, moderate and high yield above $75 \%$ correct response, good, positive attitude and performance was considered satisfactory.

The questionnaire examined the validity and reliability were also fed by several experts in the attitude of the alpha Cronbach's alpha was used $(\alpha=0 / 82)$ was calculated. And KurdRychardson method was used for validation in the knowledge that that was acceptable reliability coefficient was calculated $0 / 678$. In this phase, a questionnaire was completed by 30 health workers. Data collection method was thus that after coordination with city health network management, security and authorities responsible for health centers,

Questionnaires were given to doctors in health centers to attend health centers covered by health workers questionnaires knowledge and attitude and performance by considering the documentation, which was completed by a physician.

After completing the questionnaire, the data was analyzed by using SPSS(20) software and statistical, descriptive, analytical examinations.

(independent T, man Whitney, ANOVA, Kruskal-Wallis, Chi-square and fisher) 
The level of significance in these tests $\mathrm{p}<0 / 05$ was considered.

\section{RESULTS}

In this study, 86 health workers were present at the 33/7\% (29 patients) of subjects were female and $66 / 3 \%(n=57)$ were male.

Educational level was 64\% (55 patients) of health workers have high school diploma, 25/6\% $(\mathrm{n}=22)$ holds a junior, 5/8\% (5 patients) graduate and 4/6\% (4 patients) degree were elementary. (table 1)

In relation to age, the minimum age of 25 years and maximum age of 55 years The mean (SD) age of $6 / 68 \pm 33 / 77$ and the mean age of men $6 / 04 \pm 45 / 79$ which have been statistically significant differences were together. $(\mathrm{p}<0 / 001)$.

The lowest score of knowledge, attitude and practice, respectively 7, 21 and 24 and the highest score of 21, 97 and 48 and mean scores of knowledge, attitude and practice were 2/59 $\pm 16 / 04,14 / 48 \pm 70 / 34$ and $5 / 34 \pm 42 / 5$ respectively. (Table 2 )

Table 1. Distribution of units of study based on gender and education level

\begin{tabular}{|c|c|c|c|}
\hline Frequency percentage & Frequency & & able name \\
\hline $66 / 3$ & 57 & Male & \multirow{2}{*}{ Gender } \\
\hline $33 / 7$ & 29 & Female & \\
\hline 100 & 86 & \multicolumn{2}{|r|}{ Total } \\
\hline $4 / 6$ & 4 & primary & \multirow{4}{*}{ Education level } \\
\hline $25 / 6$ & 22 & Elementary & \\
\hline 64 & 55 & Diploma & \\
\hline $5 / 8$ & 5 & $\begin{array}{l}\text { Higher } \\
\text { diploma }\end{array}$ & \\
\hline 100 & 86 & & Total \\
\hline
\end{tabular}

Of the total units of study, 38 patients (44/2\%) low level, 44 cases $(51 / 2 \%)$ had an average remaining good level. (Table 3) 
Table 2. Descriptive statistics, knowledge, attitude and performance of the units of study

\begin{tabular}{|c|c|c|c|c|}
\hline $\begin{array}{l}\text { Standard } \\
\text { deviation }\end{array}$ & Average & $\begin{array}{c}\text { Most } \\
\text { amount }\end{array}$ & $\begin{array}{c}\text { Least } \\
\text { amount }\end{array}$ & Variable \\
\hline $2 / 59$ & $16 / 04$ & 21 & 7 & Knowledge \\
\hline $14 / 48$ & $70 / 34$ & 97 & 21 & Prespective \\
\hline $5 / 34$ & $42 / 5$ & 48 & 24 & Performance \\
\hline
\end{tabular}

Table 3. Distribution of knowledge that units of study of the referral system

\begin{tabular}{ccc}
\hline Frequency percentage & Frequency & Rank \\
\hline $44 / 2$ & 38 & Weak \\
\hline $51 / 2$ & 44 & Average \\
\hline $4 / 6$ & 4 & Good
\end{tabular}

And a total of 40 subjects $(46 / 5 \%)$ than negative, 26 cases $(30 / 2 \%)$ than moderate, and 20 cases $(23 / 3 \%)$ had a positive attitude towards the referral system. (Table 4$)$

The referral system and the performance of health workers out of a total of 40 subjects $(46 / 5 \%)$ had poor performance and others were relatively good yield. (Table 5)

Table 4. Frequency distribution of health workers surveyed attitudes towards the referral system

\begin{tabular}{cccc}
\hline $\begin{array}{c}\text { Frequency } \\
\text { percentage }\end{array}$ & Frequency & & Rank \\
& & & \\
\hline $30 / 5$ & 26 & & Negative \\
\hline $23 / 3$ & 20 & Average \\
\hline
\end{tabular}

68 health workers (79/1\%) Information on care, follow-up and referral fully documented, 17 cases $(19 / 8 \%)$ and partly recorded $1(1 / 2 \%)$ had not registered information at all. (table 6) Job performance of health workers in this study is based on four main aspects in the process of implementing the referral system consists of routine care, identify cases requiring referral, referral of confirmed cases to levels higher follow-up of cases referred in four groups aimed at children under 5 years old, young, non-communicable and pregnant women were studied. The 
results showed that the mean and standard deviation of the participants in various aspects yield is $1 / 32 \pm 10 / 84,1 / 45 \pm 10 / 54,1 / 44 \pm 10 / 57$ and $1 / 6 \pm 10 / 54$ ( table 7 )

Table 5. Distribution of units of this level of performance compared to the reference system

\begin{tabular}{cccc}
\hline Frequency percentage & Frequency & Rank \\
\cline { 1 - 1 } & $46 / 5$ & 46 & Fot desirable \\
\hline $53 / 5$ & 0 & Desirly desirable \\
\hline 0 & & Desle \\
\hline
\end{tabular}

Table 6. Distribution of registration system of units of study in the referral system

\begin{tabular}{cccc}
\hline Frequency percentage & Frequency & & Variable \\
\cline { 1 - 2 } & 68 & & Fully registered \\
\hline $19 / 8$ & 17 & Fairly registered \\
\hline $1 / 2$ & 1 & Not registered \\
\hline 100 & 86 & Total \\
\hline
\end{tabular}

Table 7. Mean and standard deviation units of study different aspects of functioning referral system.

\begin{tabular}{ccc}
\hline Standard deviation & Average & Performance scale \\
\cline { 2 - 3 } $1 / 32$ & $10 / 84$ & Taking routine care \\
\hline $1 / 45$ & $10 / 54$ & Identify cases requiring referral \\
\hline $1 / 44$ & $10 / 57$ & Referral of confirmed cases to higher \\
& & levels \\
\hline $1 / 6$ & $10 / 54$ & Follow-up of referrals \\
\hline
\end{tabular}

86 health workers in the study, the mean and standard deviation of knowledge, attitude and practice in both men and women and the significance level was calculated. Mann-Whitney test knowledge score in both groups significant difference between men and women $(p=0 / 34)$ performance score in both sexes $(\mathrm{p}=0 / 78)$ did not show.

And using independent t-test showed significant differences between the two sexes attitude. 
$(\mathrm{p}=0 / 77)$ (Table 8).

Table 8. Comparison of the mean score of knowledge, attitude and practice of health workers in the two sexes

\begin{tabular}{|c|c|c|c|c|}
\hline $\begin{array}{c}\text { Level of } \\
\text { significance }\end{array}$ & $\begin{array}{l}\text { Standard } \\
\text { Deviation }\end{array}$ & Average & Sex & Variable \\
\hline \multirow{2}{*}{$0 / 34$} & $2 / 32$ & $15 / 91$ & Female & \multirow{2}{*}{ Knowledge } \\
\hline & $3 / 09$ & $16 / 31$ & Male & \\
\hline \multirow{2}{*}{$0 / 77$} & $12 / 97$ & $70 / 66$ & Female & \multirow{2}{*}{ Prespective } \\
\hline & $17 / 31$ & $69 / 72$ & Male & \\
\hline \multirow{2}{*}{$0 / 78$} & $4 / 85$ & $42 / 78$ & Female & \multirow{2}{*}{ Performance } \\
\hline & $6 / 26$ & $41 / 96$ & Male & \\
\hline
\end{tabular}

The mean and standard deviation of knowledge, attitude and practice in education levels and the level of significance was calculated. Kruskal-Wallis test showed no significant difference between knowledge and attitude There are different levels of students ( $p>0 / 05)$. And using this test a significant difference was observed between the performance of different levels of students. $(\mathrm{p}<0 / 05)$. (Table 9).

Chi-square $(\mathrm{k} 2)$ test showed that the units of study material on various aspects of the referral system not affect their performance. (Table 10)

Fisher's exact test showed that after performing routine care and identify cases requiring referral by health workers with different levels of students study there was a significant relationship. $(\mathrm{p}<0 / 05)$

But after referral and follow forecast there is no significant relationship with level of education. ( $\mathrm{p}>0 / 05)$. (Table 11). 
Table 9. Comparison of the mean score of knowledge, attitude and practice of health workers at different levels of education study

\begin{tabular}{|c|c|c|c|c|}
\hline $\begin{array}{c}\text { Level of } \\
\text { significance }\end{array}$ & $\begin{array}{l}\text { Standard } \\
\text { deviation }\end{array}$ & Average & Education level & Variable \\
\hline \multirow{4}{*}{$0 / 45$} & $3 / 69$ & $15 / 5$ & Primary & \multirow{4}{*}{ Knowledge } \\
\hline & $1 / 91$ & $15 / 59$ & Elementary & \\
\hline & $2 / 77$ & $16 / 14$ & Diploma & \\
\hline & $2 / 4$ & $17 / 4$ & Post diploma & \\
\hline \multirow{4}{*}{$0 / 24$} & $26 / 98$ & 75 & Primary & \multirow{4}{*}{ Prespective } \\
\hline & $14 / 1$ & $74 / 68$ & Elementary & \\
\hline & $13 / 46$ & $68 / 3$ & Diploma & \\
\hline & $15 / 37$ & 70 & Post diploma & \\
\hline \multirow{4}{*}{$0 / 04$} & $7 / 76$ & $35 / 5$ & Primary & \multirow{4}{*}{ Performance } \\
\hline & $6 / 22$ & 41 & Elementary & \\
\hline & $5 / 86$ & $42 / 83$ & Diploma & \\
\hline & $5 / 12$ & $41 / 4$ & Post diploma & \\
\hline
\end{tabular}

Table 10. The relationship between different dimensions studied the performance of health workers in the referral system and gender

\begin{tabular}{|c|c|c|c|c|}
\hline \multirow{3}{*}{$\begin{array}{c}\text { Level of } \\
\text { significance }\end{array}$} & Fairly desirable & Not desirable & Donl & \multirow{2}{*}{ Performance scale } \\
\hline & & & & \\
\hline & $\begin{array}{l}\text { Amount } \\
\text { (percent) }\end{array}$ & $\begin{array}{l}\text { Amount } \\
\text { (percent) }\end{array}$ & Sex & \\
\hline \multirow{2}{*}{$0 / 19$} & $43(75 / 4)$ & $14(24 / 6)$ & Female & \multirow{2}{*}{ Taking routine care } \\
\hline & $18(62 / 1)$ & $11(37 / 9)$ & Male & \\
\hline \multirow{2}{*}{$0 / 94$} & $31(54 / 4)$ & $26(45 / 6)$ & Female & \multirow{2}{*}{$\begin{array}{c}\text { Identify cases requiring } \\
\text { referral }\end{array}$} \\
\hline & $16(55 / 2)$ & $13(44 / 8)$ & Male & \\
\hline \multirow{2}{*}{$0 / 93$} & $32(56 / 1)$ & $25(43 / 9)$ & Female & \multirow{2}{*}{$\begin{array}{l}\text { Referral of confirmed } \\
\text { cases to higher levels }\end{array}$} \\
\hline & $16(55 / 2)$ & $13(44 / 8)$ & Male & \\
\hline \multirow{2}{*}{$0 / 7$} & $29(50 / 9)$ & $28(49 / 1)$ & Female & \multirow{2}{*}{ Follow-up of referrals } \\
\hline & $16(55 / 2)$ & $13(44 / 8)$ & Male & \\
\hline
\end{tabular}


Table 11. The relationship between different dimensions studied the performance of health workers in the referral system and level of education

\begin{tabular}{|c|c|c|c|c|c|c|}
\hline \multirow{2}{*}{$\begin{array}{c}\text { Level of } \\
\text { significance }\end{array}$} & $\begin{array}{c}\text { Post } \\
\text { diploma }\end{array}$ & Diploma & Elementary & Primary & $\begin{array}{c}\text { Education } \\
\text { level }\end{array}$ & \multirow{2}{*}{$\begin{array}{c}\text { Performance } \\
\text { scale }\end{array}$} \\
\hline & $\begin{array}{l}\text { Amount } \\
\text { (percent) }\end{array}$ & $\begin{array}{l}\text { Amount } \\
\text { (percent) }\end{array}$ & $\begin{array}{l}\text { Amount } \\
\text { (percent) }\end{array}$ & $\begin{array}{l}\text { Amount } \\
\text { (percent) }\end{array}$ & Rank & \\
\hline $0 / 03$ & $\begin{array}{l}2(0 / 8) \\
3(4 / 9)\end{array}$ & $\begin{array}{c}11(44) \\
44(72 / 1)\end{array}$ & $\begin{array}{c}9(36) \\
13(21 / 3)\end{array}$ & $\begin{array}{l}3(12) \\
1(1 / 6)\end{array}$ & $\begin{array}{c}\text { Not } \\
\text { desirable } \\
\text { Fairly } \\
\text { desirable }\end{array}$ & $\begin{array}{c}\text { Taking routine } \\
\text { care }\end{array}$ \\
\hline $0 / 031$ & $\begin{array}{l}2(5 / 1) \\
3(6 / 4)\end{array}$ & $\begin{array}{l}20(51 / 3) \\
35(74 / 5)\end{array}$ & $\begin{array}{l}13(33 / 3) \\
9(19 / 1)\end{array}$ & $\begin{array}{c}4(10 / 3) \\
0(0)\end{array}$ & $\begin{array}{c}\text { Not } \\
\text { desirable } \\
\text { Fairly } \\
\text { desirable }\end{array}$ & $\begin{array}{c}\text { Identify cases } \\
\text { requiring } \\
\text { referral }\end{array}$ \\
\hline $0 / 5$ & $\begin{array}{l}3(7 / 9) \\
2(4 / 2)\end{array}$ & $\begin{array}{l}22(57 / 9) \\
33(68 / 8)\end{array}$ & $\begin{array}{c}10(26 / 3) \\
12(25)\end{array}$ & $\begin{array}{l}3(7 / 9) \\
1(2 / 1)\end{array}$ & $\begin{array}{c}\text { Not } \\
\text { desirable } \\
\text { Fairly } \\
\text { desirable }\end{array}$ & $\begin{array}{c}\text { Referral of } \\
\text { confirmed } \\
\text { cases to higher } \\
\text { levels }\end{array}$ \\
\hline $0 / 9$ & $\begin{array}{l}2(4 / 9) \\
3(6 / 7)\end{array}$ & $\begin{array}{c}25(61) \\
30(66 / 7)\end{array}$ & $\begin{array}{l}12(29 / 3) \\
10(22 / 2)\end{array}$ & $\begin{array}{l}2(4 / 9) \\
2(4 / 4)\end{array}$ & $\begin{array}{c}\text { Not } \\
\text { desirable } \\
\text { Fairly } \\
\text { desirable }\end{array}$ & $\begin{array}{c}\text { Follow-up of } \\
\text { referrals }\end{array}$ \\
\hline
\end{tabular}

\section{DISCUSSION}

The results of this study showed that the mean score of knowledge, attitude and practice of health workers in relation to the referral system $2 / 59 \pm 16 / 04$ of $26,14 / 48 \pm 70 / 34105$ and $5 / 34 \pm 42 / 5$ of 48 helped according to present knowledge and practice mean scores of attitude than the average score was higher than the reference system.

According to the researchers observed a fairly comprehensive searches in connection with the referral system was found in other studies, this finding is consistent with results Ajami et al[18] and Balali Maibodi et al [9]regarding the knowledge, attitude and performance of 
health workers was similar in regard to oral health.

Out of the 86 units of study $44 / 2 \%$ of them were in poor rating and 51/2\% on average in the level of awareness of the referral system, and only $4 / 6 \%$ of the ratings were good and the highest score achieved in knowledge, 21 was obtained.

Accordingly, the majority of health workers had moderate knowledge to issue with regard to the important responsibility of health workers in the health system and their significant impact on the proper implementation of the referral system, it was expected for them to have more knowledge.

The results obtained were compatible with the study conducted by Khani et al in conjunction with health professionals to assess the awareness of breast cancer prevention programs. The results of the study showed that half of the study participants had intermediate to weak awareness in this field[ 12] . However, in the study conducted Al-Erian et al captured in Saudi Arabia Knowledge of the relationship between public and private sectors in relation to the referral system was Not consistent with our findings.[ 14]

In the attitude study, only $23 / 3 \%$ of the subjects were observed for the positive attitude towards the referral system in line with the findings of Al-Erian et al .[ 14]

In the study conducted by Naghibi et al, $76 / 4 \%$ of health workers had a positive attitude towards BSE[11].The two studies, in this respect, were incompatible with each other.

Perhaps the main reason to justify this contradiction in results was attributable to differences in population. In this study, the subjects were all male and female health workers, but in the study conducted by Naghibi et al only female health workers were studied.

It is obvious that there is a negative attitude towards the referral system a significant percentage of those who have a positive attitude to conduct proper referral system in others and build community coverage have considerable concerns and must recognize, monitor and correct the causes and motivation of health workers and the enhancement of knowledge,in order to address this important cause. [11]

And in the total performance $100 \%$ of subjects with undesirable and less desirable performance in implementing the referral system was seen and none of them had desirable performance in this area. Perhaps low education system and the quality of supervision and 
control of health house is the main justification for this matter.

And in the study conducted by Nasrallah pourshirvani et al in the northern provinces of Iran, in line with our findings, referral system performance was less than expected.[19]

In total, the score obtained indicate the need for careful monitoring and evaluation of training programs in order to improve knowledge, attitude and performance of health workers in relation to the referral system. The findings in this study showed that the mean score of knowledge, attitude and practice in the two sexes are not different from each other.

The results in this field was compatible with some of the results Amiri and Kassaian conducted in Shahrood city. In that study, a significant relationship between knowledge and sex by service providers, there was no significant relationship between attitude and sex .[20] In a study conducted by Khademi et al in Esfahan in line with the conclusions of this study there was no significant difference between knowledge and practice in both sexes[21] While in the study conducted by Karimi et al in the city of Saveh results showed that female health awareness had better performance than their male health workers[8] and the results of Tada et al in Japan was consistent with our findings[13]. In order to clarify the relationship between gender and foregoing there is a need for further studies with larger sample size.

In the present study, no significant difference between knowledge, attitudes were observed with increasing education The findings of the study are compatible with Taghizadeh et al in Tabriz[10] whereas Balali Maibodi et al [9] and Ajami et al [18] in Mashhad Health Center's staff observed a significant association between knowledge and attitude with educational level. In line with studies Karimi et al in Saveh results of this study showed that the performance of health workers in connection with the referral system had a significant relationship with education level and health workers with high literacy levels are better than those with primary education level and fifth grade degree holders.

It seems that higher education is a tool for more empowerment in health workers in skills.

Several studies have shown that the role of health literacy in general more than income and jobs and illiteracy could be a feeling of responsibility for health affairs.[8]

Performance of health workers in the implementation of the referral system includes the main four-dimensions (routine care procedures to identify cases requiring referral, referral and 
follow-up) that the study didn't find a significant relationship between these dimensions and sex while a significant relationship was seen between the dimensions of taking care and identifying cases requiring referral with the level of education. to explain this finding it can be said that proper implementation of the first two dimensions requires health information and service education through instructions that higher education is one of the factors in this regard but two other dimensions are practical, which requires high motivation in the service provider and appropriate interaction between team members and their contribution to the health of the population covered by health.

No study with similar findings to this study was found.

\section{CONCLUSION}

In general it can be said that despite the responsibility and important role of health workers as the most peripheral health team members in implementing the referral system and also considering the fact that the majority of the population under study knowledge and attitudes towards the referral system is less than expected, Perhaps the lack of training or inadequate training of health workers can be concluded that in the context of the referral system and the lack of emphasis on its implementation by the city health department officials and experts, the implementation of this system has a problem. Therefore, in order to improve their knowledge and attitude to good and positive attitude and understanding of the issues affecting it and to further elucidate the factors affecting the performance, interventions and health education programs in order to empower health workers is necessary.

And it is also recommended that it is necessary to have more accurate monitoring and evaluation and by authorities to identify strong points and areas for improvement and improvement of the referral process.

\section{ACKNOWLEDGMENT}

Hereby, we kindly thank the department of health of Golestan University of Medical Sciences , and also head of Ramian city's Health center for facilitating the Implementation of the program, and we also thank all health team members implementing the family physician 
program of the health centers who helped us gather the required data .

\section{REFERENCES}

[1] Ahmadian M , Bankian Tabrizi E, Rezaie Haghighat M, Evaluating referral system performance in family physician program, In the collection of seminar articles, the role of family physician in health system. Mashhad university Department of health, June 2012:36

[2] Bahadori M, Ebadzadeh F, Rashid Y, namazi A, checking the status of the worker about the purposes and the importance of family physician referral system in North Khorasan-city of Shirvan in 2011. In the collection of seminar articles, the role of family physician in health system. Mashhad university Department of health, June 2012:4

[3] Bagheri Lankarani K, position of health workers in the view of the Minister of Health and Medical Education drugs. Social workers Quarterly.2008 ,18 (4): 2-3.

[4] Habibzadeh SR ,family physician and referral system, challenges and hope. In the collection of seminar articles, the role of family physician in health system. Mashhad university Department of health, June 2012:192

[5] Nasrollahpour Shirvani SD,Ashrafian Amiri H, Motlagh ME, Kabir MJ, Maleki M R, Shabestani Monfared A, Alizadeh R, Evaluation of the Function of Referral System in Family Physician Program in Northern Provinces of Iran: 2008.Journal of Babol University of Medical Sciences. $2010,1(6):$ 46-52.

[6] Coleman P, Irons R,Nicholl J,Will alternative immediate care services reduce demand for non-urgent treatment at accident and emergency. Emerg Med J . 2001, 18(6):482-7.

[7] Ostovar R ,Malekzadeh JM, Afshun S, Farhadi N, The attitude of health workers and doctors working in primary health care providers in the city of Boyer Ahmad of the referral system in 2000. Journal of Yasouj medical science.2002,7 (25): 37-41.

[8] Karimi M, Saidi Nick M, choobdaran KH, Khorram R, Baradaran H, Koohpayeh Esfahani J, Assessment of Knowledge, Attitude and Practice Educational Needs of Health Care Providers (Behvarzan) Working toward Maternal Health in Health Networks in S aveh. Journal of Torbat University of Medical Sciences.2013, 1 (4): 62-67.

[9] Balali Maibodi F, Mahmoodi Zarand M, Hasani M, Knowledge, Attitude and Practice of 
Health Workers Working in the Southern Cities of Kerman Province about Oral and Dental Health in 2009. Journal of Rafsanjan University Of Medical Sciences.2011 ,10 (1): 69-74.

[10] Taghizadeh Ganji A, Jafari A, Poorqholy N, Iranizadeh H, Evaluation of knowledge, attitude and practice of Tabriz's school health workers about oral and dental health. Journal of Dentistry of Tehran University of Medical Sciences and Health Services.2009, 22 (3): 132-138.

[11] Naghibi SA, VahidShahi K, Yazdani J, Nushnayi F, knowledge, attitude and practice of female health workers Maku city about BSE, Scientific Journal of School of Public Health and Institute of Public Health Research.2009 ,7 (2): 61-68 .

[12] Khani H, Moslemizadeh N, Montazeri A, Godazandeh GA, Ghorbani A, knowledge, attitudes and practices among Iranian health workers in southern coastwise of the Caspian Sea ,Iranian Journal of Breast Diseases.2008, 1 (2): 28-37.

[13] Tada A, Hanada N,Sexual differencein oral health behavior in Japanese yong adults. Public healts.2004,118(2):104-109.

[14] Al-Erian RA, Mahfouz AA, Alakija W,Al-Khozayem A A, Referral system in the Asir Region, Saudi Arabia: knowledge, attitude, and practice of physicians working in urban areas--a comparative study of governmental and private health sectors . J Egypt Public Health Assoc.1994,69(1-2):65-75

[15] Azizi Motlagh, T, Hosseininiaz N, Hashemian V, Behvarz interaction with the health team,Journal of health workers.2013, 24 (87): 28-30.

[16] Hossein Pour M, bamorovvat Nejad E, of health workers in the insurance operations and their rights, Journal of health workers.2007, 18 (1): 23.

[17] Mosleh A, Rezaei M, Evaluation of Drug Prescription to under-5-year-old Children by Junior Paramedics in Rey City 2002. Journal of Kermansha University of Medical Sciences.2007,11 (1): 157-168.

[18] Ajami B,Shabzendehdar M, Asadollahi A, Evaluation of Oral Health Knowledge, Attitude and Behaviour of Employees in Mashhad Health Centers No 1, 2 and 3 in 2006.Journal of Mashhad Dental School.2008, 32 (1): 37-40. 
[19] Nasrollahpour Shirvani D, Ashrafian Amiri H, Motlagh M E , Kabir M J , Maleki M R, Shabestani Monfared A ,Alizadeh R, Evaluation of the Function of Referral System in Family Physician Program in Northern Provinces of Iran: 2008. journal of Babol university of medical sciences.2010,11(6):40-52. [Persian]

[20] Amiri M, Kasaeian A, Study of Family Planning Service Providers' Knowledge about and Attitude toward Pregnancy Prevention Methods, Journal of Knowledge \& Health.2009, (1) $4: 24-29$.

[21] Khademi H, kaviani N, Araghizadeh AM, Jafari MR, Knowledge and attitudes of Isfahan township's Behvarzes toward prevention of oral and dental diseases. Journal of Hormozgan University of Medical Sciences.2007, 11 (1): 91-95.

\section{How to cite this article:}

Zahra Asadi A, Iravan Masoudi Asl B and Sayed Jamale Din Tabibi C. The effect of health workers' performance on implementation of the referral system in family physician program in ramian city. J. Fundam. Appl. Sci., 2016, 8(3S), 786-802. 